\section{OPEN ACCESS}

Edited by:

Azad Eshghi,

UVic Genome BC Protein Centre,

Canada

Reviewed by:

Christopher J. Pappas,

Manhattanville College, United States

J. Christopher Fenno,

University of Michigan, United States

Peter Kraiczy,

Goethe University Frankfurt, Germany

*Correspondence:

Angela S. Barbosa

angela.barbosa@butantan.gov.br

Received: 27 October 2017 Accepted: 07 March 2018

Published: 27 March 2018

Citation:

da Silva LB, Menezes MC, Kitano ES, Oliveira AK, Abreu AG, Souza GO,

Heinemann MB, Isaac L, Fraga TR,

Serrano SMT and Barbosa AS (2018)

Leptospira interrogans Secreted

Proteases Degrade Extracellular Matrix and Plasma Proteins From the Host.

Front. Cell. Infect. Microbiol. 8:92.

doi: 10.3389/fcimb.2018.00092

\title{
Leptospira interrogans Secreted Proteases Degrade Extracellular Matrix and Plasma Proteins From the Host
}

\author{
Ludmila B. da Silva ${ }^{1}$, Milene C. Menezes ${ }^{2}$, Eduardo S. Kitano ${ }^{2}$, Ana K. Oliveira ${ }^{3}$, \\ Afonso G. Abreu ${ }^{4,5}$, Gisele O. Souza ${ }^{6}$, Marcos B. Heinemann ${ }^{6}$, Lourdes Isaac ${ }^{7}$, \\ Tatiana R. Fraga ${ }^{7}$, Solange M. T. Serrano ${ }^{2}$ and Angela S. Barbosa ${ }^{\text {* }}$
}

\footnotetext{
${ }^{1}$ Laboratory of Bacteriology, Butantan Institute, São Paulo, Brazil, ${ }^{2}$ Special Laboratory of Applied Toxinology, Center of Toxins, Immune-Response and Cell Signaling, Butantan Institute, São Paulo, Brazil, ${ }^{3}$ Brazilian Biosciences National Laboratory, Brazilian Center for Research in Energy and Materials, Campinas, São Paulo, Brazil, ${ }^{4}$ Postgraduation Program in Parasitic Biology, CEUMA University, São Luís, Brazil, ${ }^{5}$ Postgraduation Program in Health Sciences, Federal University of Maranhão, São Luís, Brazil, ${ }^{6}$ Department of Preventive Veterinary Medicine and Animal Health, School of Veterinary Medicine and Animal Science, University of São Paulo, São Paulo, Brazil, ${ }^{7}$ Department of Immunology, Institute of Biomedical Sciences, University of São Paulo, São Paulo, Brazil
}

Leptospires are highly motile spirochetes equipped with strategies for efficient invasion and dissemination within the host. Our group previously demonstrated that pathogenic leptospires secrete proteases capable of cleaving and inactivating key molecules of the complement system, allowing these bacteria to circumvent host's innate immune defense mechanisms. Given the successful dissemination of leptospires during infection, we wondered if such proteases would target a broader range of host molecules. In the present study, the proteolytic activity of secreted leptospiral proteases against a panel of extracellular matrix (ECM) and plasma proteins was assessed. The culture supernatant of the virulent $L$. interrogans serovar Kennewicki strain Fromm (LPF) degraded human fibrinogen, plasma fibronectin, gelatin, and the proteoglycans decorin, biglycan, and lumican. Interestingly, human plasminogen was not cleaved by proteases present in the supernatants. Proteolytic activity was inhibited by 1,10-phenanthroline, suggesting the participation of metalloproteases. Moreover, production of proteases might be an important virulence determinant since culture-attenuated or saprophytic Leptospira did not display proteolytic activity against ECM or plasma components. Exoproteomic analysis allowed the identification of three metalloproteases that could be involved in the degradation of host components. The ability to cleave conjunctive tissue molecules and coagulation cascade proteins may certainly contribute to invasion and tissue destruction observed upon infection with Leptospira.

Keywords: Leptospira, secreted proteins, extracellular matrix, plasma proteins, host invasion 


\section{INTRODUCTION}

Leptospira are long, thin, spiral-shaped, and highly motile Gramnegative bacteria. These spirochetes can be either non-pathogenic free-living organisms or pathogenic, having the potential to cause disease in animals and humans. During infection, leptospires invade multiple organs and tissues, and damage the endothelial linings of the small blood vessels. Severe cases of leptospirosis are characterized by multiple symptoms that may include vascular injury, thrombocytopenia, jaundice, kidney failure, pulmonary hemorrhage, and ocular manifestations such as uveitis and conjunctival congestion (Levett, 2001).

Pathogenic leptospires efficiently spread and propagate in susceptible hosts. They are equipped with strategies to modulate the surrounding microenvironment in the host, including mechanisms to circumvent host's immune responses (Meri et al., 2005; Barbosa et al., 2009). The secretion of proteases that inactivate essential host proteins is an important tool used by diverse microorganisms during the colonization process. Leptospira is no exception to this phenomenon, since pathogenic strains have been shown to secrete proteases capable of degrading several proteins of the complement cascade, contributing to serum resistance (Fraga et al., 2014; Amamura et al., 2017). Many bacterial proteolytic enzymes can be considered virulence factors. By hydrolyzing diverse proteinaceous substrates of the host, bacterial proteases play a crucial role in colonization and spreading, allowing evasion of innate immune responses and contributing to disruption of tissue integrity.

The knowledge on the mechanisms underlying tissue damage during leptospirosis is still limited. Like other bacteria, leptospires cross epithelial and endothelial host barriers to get access to target organs. Adhesion to and degradation of the extracellular matrix (ECM), notably of basement membranes, are certainly required for invasion. To date, few studies have been conducted to experimentally identify and characterize leptospiral proteases. It has been shown that a number of Leptospira serovars produce multiple gelatinases ranging from 32 to 240 $\mathrm{kDa}$ (Madathiparambil et al., 2011). One of them, named ColA, was further characterized and was shown to hydrolyze different types of collagen. A colA mutant strain displayed attenuated transcytosis through human embryonic kidney cell lineage HEK293 and human umbilical vein endothelial cell (HUVEC) monolayers, and reduced virulence in the hamster model of infection. A reduced number of bacteria in organs of animals infected with the mutant strain was also observed (Kassegne et al., 2014). Leptallo I, a protease that belongs to the M23 family, displays proteolytic activity against elastin. Leptallo I was shown to be secreted to the culture medium during leptospiral growth, and IgG antibodies recognizing the protein could be detected in the sera of patients with laboratory-confirmed leptospirosis (Hashimoto et al., 2013).

In a previous work, we reported the secretion of proteases by pathogenic Leptospira as a novel complement evasion mechanism displayed by these spirochetes (Fraga et al., 2014). Given the rapid and successful dissemination of leptospires during infection, we can assume that such proteases target a broader range of host molecules. As such, the purpose of this work was to evaluate the proteolytic activity of secreted leptospiral proteases against a panel of ECM and plasma proteins.

\section{MATERIALS AND METHODS}

\section{Proteins, Antibodies, and Plasma}

Fibrinogen, plasminogen, thrombin and fibronectin from human plasma, laminin from basement membrane Engelbreth-HolmSwarm (EHS) murine sarcoma, and decorin from bovine articular cartilage were purchased from Sigma-Aldrich. Gelatin and Matrigel from EHS murine sarcoma were purchased from Difco and BD Biosciences, respectively, and the recombinant proteoglycans lumican (human), and biglycan (human) were purchased from R\&D Systems. Rabbit anti-human fibrinogen was from Sigma-Aldrich. Depletion of albumin from human plasma was performed according to Subramanian (1984).

\section{Leptospira Strains}

The Leptospira strains used were L. biflexa serovar Patoc strain Patoc I, L. biflexa serovar Andamana strain CH11, L. interrogans serovar Kennewicki strain Fromm (LPF), L. interrogans serovar Copenhageni strain 10A, L. interrogans serovar Pomona strain Pomona, L. kirshneri serovar Cynopteri strain $3522 \mathrm{C}$, and L. noguchi serovar Panama CZ 214. Virulence of LPF was maintained by iterative passages in hamsters. Infected animals become acutely ill and present symptoms such as jaundice, uveitis, light sensitivity, prostration, loss of appetite. They usually die on day 5 post-infection. Bacteria were cultured for 7 days in modified Ellinghausen-McCullough-Johnson-Harris $(\mathrm{EMJH})$ at $29^{\circ} \mathrm{C}$ under aerobic conditions as previously described (Barbosa et al., 2010). The leptospires were then washed, counted by dark-field microscopy, and $1 \times 10^{9}$ bacteria resuspended in PBS ( $\mathrm{pH}$ 7.4) were allowed to secrete proteins for $4 \mathrm{~h}$ at $37^{\circ} \mathrm{C}$, thus simulating responses to temperature upshift observed during infection of mammalian hosts (Fraga et al., 2014). Protein concentration was determined using the BCA Kit (Pierce).

\section{Degradation of Plasma and ECM Molecules}

Fibrinogen $(15 \mu \mathrm{g})$, plasminogen $(5 \mu \mathrm{g})$, fibronectin $(5 \mu \mathrm{g})$, thrombin $(1 \mu \mathrm{g})$, laminin $(5 \mu \mathrm{g})$, matrigel $(5 \mu \mathrm{g})$, decorin $(2 \mu \mathrm{g})$, biglycan $(2 \mu \mathrm{g})$, and lumican $(2 \mu \mathrm{g})$ were incubated with culture supernatants from different Leptospira strains $(0.5 \mu \mathrm{g})$ at $37^{\circ} \mathrm{C}$ for the indicated time points. A sample of each substrate was also incubated without culture supernatants for $18 \mathrm{~h}$ under identical conditions. Reactions were stopped by adding Laemmli sample buffer (60 mM Tris-Cl pH 6.8, 2\% SDS, 10\% glycerol, $5 \% \beta$-mercaptoethanol, $0.01 \%$ bromophenol blue) and subjected to SDS-PAGE. Polyacrylamide gels were subsequently stained. Degradation of fibrinogen in plasma was assessed as follows. Albumin-depleted human plasma $(15 \mu \mathrm{g})$ was incubated with LPF supernatant $(0.01-0.5 \mu \mathrm{g})$ for $2 \mathrm{~h}$ at $37^{\circ} \mathrm{C}$ and then submitted to SDS-PAGE followed by electroblotting onto nitrocellulose membrane. Cleavage products were detected using rabbit anti-human fibrinogen antibodies, followed by peroxidaseconjugated anti-rabbit antibodies. Positive signals were detected 
by enhanced chemiluminescence (West Pico, Pierce). To assess the class of proteases involved in the degradation of ECM and plasma proteins, leptospiral supernatants were preincubated with inhibitors of serine $(5 \mathrm{mmol} / \mathrm{L}$ phenylmethylsulfonyl fluoride), metallo- (5 $\mathrm{mmol} / \mathrm{L}$ 1,10-phenanthroline), cysteine $(28 \mu \mathrm{mol} / \mathrm{L} \quad \mathrm{E}-64)$ or aspartyl $(5 \mu \mathrm{mol} / \mathrm{L}$ pepstatin) proteases for $30 \mathrm{~min}$ before the addition of the substrate.

\section{Gelatin Zymography}

To assess gelatinolytic enzymatic activity in Leptospira culture supernatants zymography using gelatin was performed. Gelatin $(1 \mathrm{mg} / \mathrm{mL})$ was copolymerized with $12 \% \mathrm{w} / \mathrm{v}$ acrylamide, $0.3 \%$ bisacrylamide and $0.375 \mathrm{M}$ Tris- $\mathrm{HCl}(\mathrm{pH} 8.8)$. Samples $(0.5 \mu \mathrm{g}$ of proteins from culture supernatants) were mixed with nonreducing SDS-PAGE sample buffer (40 $\mathrm{mM}$ Tris $\mathrm{HCl} \mathrm{pH} 6.8,1 \%$ SDS, $2 \%$ glycerol and $0.01 \%$ bromophenol blue) and applied to gels. After electrophoresis, the gels were incubated for $30 \mathrm{~min}$ at room temperature on a rotary shaker in $50 \mathrm{mM}$ Tris- $\mathrm{HCl}$, $\mathrm{pH} 7.4$, containing 2.5\% Triton X-100. Excess Triton X-100 was removed upon washes with deionized water and then the gels were incubated in a buffer containing $0.05 \mathrm{M}$ Tris- $\mathrm{HCl}, \mathrm{pH} 8.0$, $0.15 \mathrm{M} \mathrm{NaCl}, 0.01 \mathrm{M} \mathrm{CaCl}_{2}, 0.02 \% \mathrm{CHAPS}$ at $37^{\circ} \mathrm{C}$ for $12 \mathrm{~h}$. The gels were stained with Coomassie blue and destained. Gelatin digestion was identified as clear zones of lysis against a blue background.

\section{Mass Spectrometry and Protein Identification}

L. interrogans (LPF) and L. biflexa (Patoc I) ( $10^{9}$ bacteria) cultured in EMJH medium at $29^{\circ} \mathrm{C}$ were pelleted by centrifugation at $3,200 \times \mathrm{g}$ for $15 \mathrm{~min}$, and washed twice with PBS, $\mathrm{pH}$ 7.4. The bacteria were resuspended in PBS and incubated at $37^{\circ} \mathrm{C}$ for $4 \mathrm{~h}$ to allow secretion of proteins, and centrifuged at $3,200 \times \mathrm{g}$ for $10 \mathrm{~min}$. Supernatants were collected, passed through a $0.22 \mu \mathrm{m}$ filter (Merck Millipore), and concentrated using Amicon Ultra centrifugal filters (3,000 MWCO; Merck Millipore).

For the identification of Leptospira secreted proteins, $30 \mu \mathrm{g}$ of proteins derived from LPF and Patoc I culture supernatants (three biological replicates) were processed by the Filter Aided Sample Preparation (FASP) procedure (Wiśniewski et al., 2009), using $10 \mathrm{kDa}$ Microcon filtration devices (Millipore). The resulting protein mixture was diluted to $0.06 \mathrm{~mL}$ of $0.05 \mathrm{M}$ $\mathrm{NH}_{4} \mathrm{HCO}_{3}$ and trypsin (Sigma) was added at a 1:50 enzymeto-substrate ratio, and submitted to incubation at $37^{\circ} \mathrm{C}$ for $18 \mathrm{~h}$. Peptide samples were desalted using StageTips C18 according to Rappsilber et al. (2007).

Each peptide mixture $(5 \mu \mathrm{L})$ was injected into a $5 \mathrm{~cm}$ Jupiter ${ }^{\circledR}$ C-18 trap column packed in-house (Phenomenex; $100 \mu \mathrm{m}$ I.D. $\times 360 \mu \mathrm{m}$ O.D.) using a EASY nanoLCII system (Thermo Fisher Scientific) coupled to an LTQ-Orbitrap Velos mass spectrometer (Thermo Fisher Scientific). Chromatographic separation of tryptic peptides was performed on a $10-\mathrm{cm}$ long column $(75 \mu \mathrm{m}$ I.D. $\times 360 \mu \mathrm{m}$ O.D.) packed in-house with $5 \mu \mathrm{m}$ Aqua ${ }^{\circledR} \mathrm{C}-18$ beads (Phenomenex). Peptides eluted with a linear gradient of 5$35 \%$ acetonitrile in $0.1 \%$ formic acid (solution B) at $200 \mathrm{~nL} / \mathrm{min}$ in
$75 \mathrm{~min}, 35-80 \%$ B in $15 \mathrm{~min}, 80 \%$ B for $7 \mathrm{~min}$, back to $5 \%$ in $1 \mathrm{~min}$ and $5 \% \mathrm{~B}$ for $22 \mathrm{~min}$. Spray voltage was set to $2.4 \mathrm{kV}$ and the mass spectrometer was operated in data dependent mode, in which one full MS scan was acquired in the $m / z$ range of 300-1,700 followed by MS/MS acquisition using collision induced dissociation of the twelve most intense ions from the MS scan. MS spectra were acquired in the Orbitrap analyzer at 60,000 resolutions (at $400 \mathrm{~m} / \mathrm{z}$ ) whereas the MS/MS scans were acquired in the linear ion trap. Isolation window, activation time and normalized collision energy were set to, respectively, $3 \mathrm{~m} / \mathrm{z}, 10 \mathrm{~ms}$ and $35 \%$. A dynamic peak exclusion was applied to avoid the same $m / z$ of being selected for the next $60 \mathrm{~s}$. Three technical replicates were performed.

LTQ-Orbitrap Velos raw data were searched using the Andromeda algorithm (Cox et al., 2011) at the MaxQuant environment (Cox and Mann, 2008; version 1.5.0.0), using a target database restricted to the genus Leptospira (UniProt database containing 366,195 protein sequences, downloaded on Nov 30, 2015) to which a set of reverse sequences were added (decoy dataset), with a parent and fragment mass tolerance of $10 \mathrm{ppm}$ and $0.5 \mathrm{Da}$, respectively. Carbamidomethylation was set as fixed modification, and oxidation of methionine, protein $\mathrm{N}$ acetylation and deamidation of asparagine or glutamine were specified as variable modifications. Two missed cleavages were allowed and the minimal length required for a peptide was seven amino acids. One unique peptide was required for protein identifications. The false discovery rate (FDR) at peptide and protein level was adjusted to $1 \%$. The output of the search was processed using Perseus (Tyanova et al., 2016; version 1.5.0.15). Contaminants, reverse decoy proteins, and proteins identified only by a modification site were removed from search. Only proteins identified in two of three biological replicate data sets were accepted.

\section{RESULTS}

\section{Degradation of ECM and Plasma Proteins by $L$. interrogans}

Degradation of structural and soluble host molecules contributes to bacterial dissemination facilitating invasion and colonization of target organs. In this work, we evaluated the proteolytic activity of leptospiral secreted proteases against ECM and plasma proteins. Secreted proteins were obtained upon incubation of leptospires at $37^{\circ} \mathrm{C}$ in $\mathrm{PBS}$ because it has been previously shown that proteolytic activity against host's complement molecules is clearly observed under these conditions (Fraga et al., 2014).

Basement membranes, predominantly composed of laminin and collagen IV, are specialized extracellular matrices that separate the epithelium and endothelium from underlying connective tissue. Since degradation of basement membrane components is crucial for invasion, we first assessed proteolytic activity of Leptospira culture supernatants against laminin and matrigel. Under our experimental conditions, laminin and matrigel were not degraded by proteins from leptospiral supernatants (Figures 1A,B). 
A

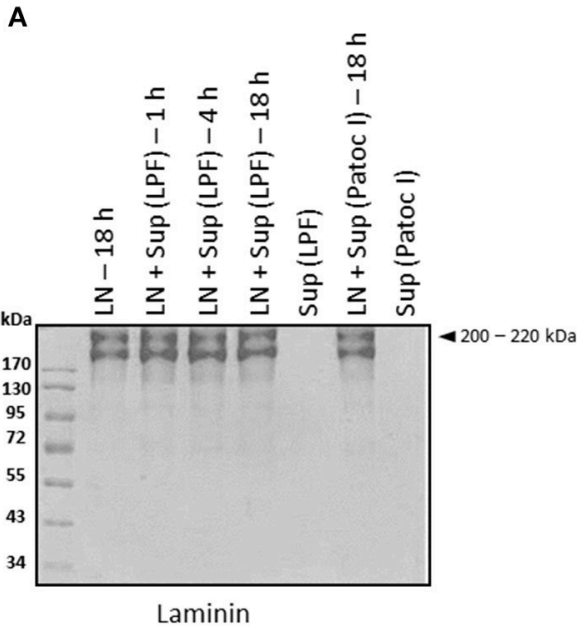

B

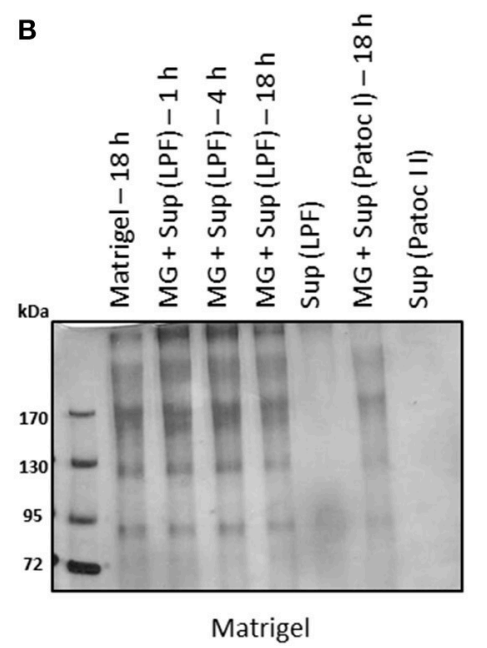

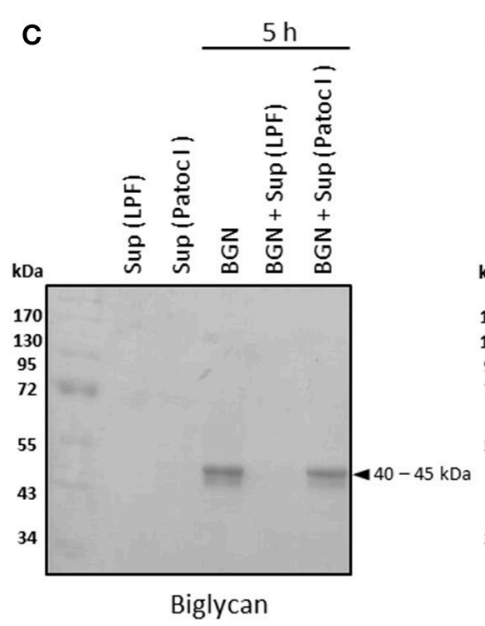

D $5 \mathrm{~h}$

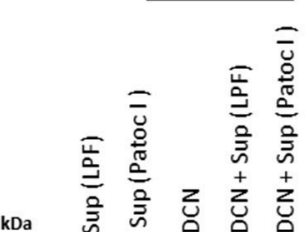

E $5 \mathrm{~h}$

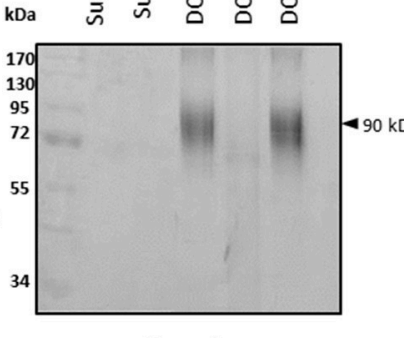

Decorin
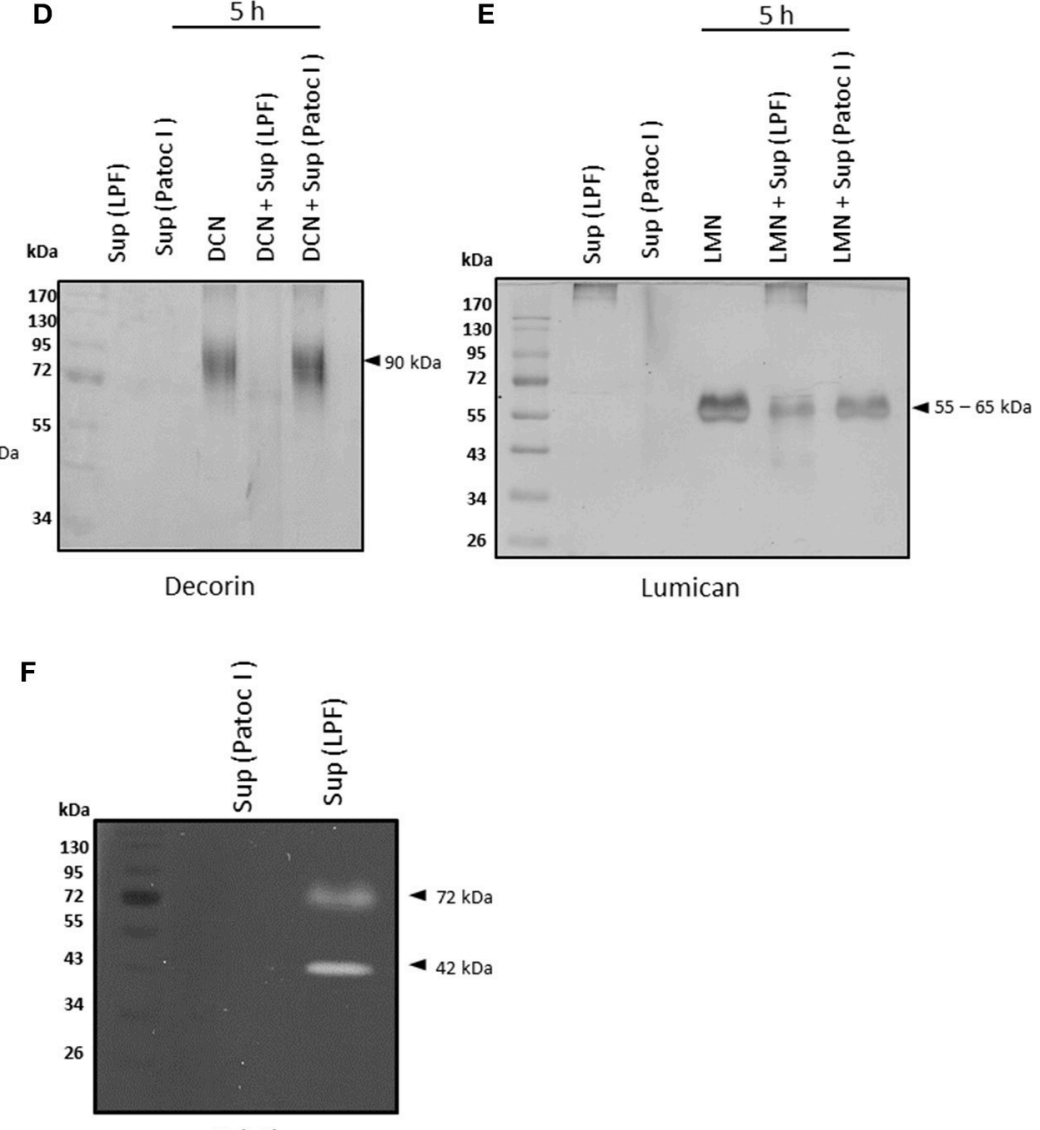

Gelatin

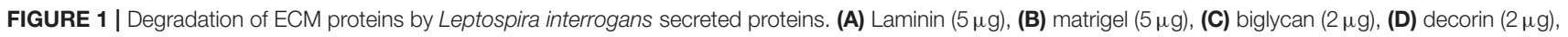
and (E) lumican $(2 \mu \mathrm{g})$ were incubated with supernatants of pathogenic Leptospira interrogans serovar Kennewicki strain Fromm (LPF) or saprophytic Leptospira biflexa serovar Patoc strain Patoc I ( $0.5 \mu \mathrm{g}$ of total secreted proteins) at $37^{\circ} \mathrm{C}$ for the indicated time points. Cleavage products were evaluated by SDS-PAGE under reducing conditions. Gels were silver stained. (F) Proteins present in both supernatants ( $0.5 \mu \mathrm{g}$ of total secreted proteins) were submitted to zymography on a $12 \%$ SDS-polyacrylamide gel copolymerized with gelatin and Coomassie Brilliant Blue stained. LN, laminin; MG, matrigel; BGN, biglycan; DCN, decorin; LMN, lumican; Sup (LPF), supernatant of Leptospira interrogans serovar Kennewicki strain Fromm; Sup (Patoc), supernatant of Leptospira biflexa serovar Patoc strain Patoc I. 
Proteoglycans, heavily glycosylated proteins, are also major components of extracellular matrices. They fill spaces in the ECM by bridging different macromolecules and provide a highly hydrated gel-like microenvironment (revised in Chagnot et al., 2012). Degradation of small leucine-rich proteoglycans (SLRP) by proteases present in leptospiral culture supernatants was also assessed. At an enzyme/substrate ratio of 1: 4, i.e., $0.5 \mu \mathrm{g}$ of supernatant: $2 \mu \mathrm{g}$ of proteoglycan, decorin and biglycan were fully degraded after incubation with the virulent strain LPF supernatant whereas lumican was partially degraded (Figures 1C-E). At an enzyme/substrate ratio of 1: 10, proteoglycan hydrolysis was much less pronounced (data not shown).

In addition, proteases of approximately 72 and $42 \mathrm{kDa}$ with gelatinolytic activity were detected in the presence of the LPF supernatant, as revealed by gel-zymography (Figure 1F). Regardless of the substrate used, no proteolytic activity was observed upon incubation with the saprophytic strain Patoc I supernatant (Figure 1).

Blood coagulation proteins such as fibrinogen, plasminogen, and thrombin, as well as plasma fibronectin, were also tested as substrates for leptospiral proteases. Plasma fibronectin and fibrinogen were time-dependently degraded by LPF proteases whereas no degradation occurred in the presence of Patoc I supernatant, even after $18 \mathrm{~h}$ of incubation (Figures 2A,B). Fibronectin fragments ranging from 25 to $170 \mathrm{kDa}$ were generated upon a prolonged incubation period (Figure 2A). Smaller fibrinogen fragments of $25-45 \mathrm{kDa}$ were also produced as a consequence of both $\alpha$ - and $\beta$-chain degradation (Figure 2B). An enzyme/substrate ratio of 1: 30 , i.e., $0.5 \mu \mathrm{g}$ of supernatant: $15 \mu \mathrm{g}$ of purified fibrinogen, seems to be the minimum required ratio for complete degradation of both $\alpha$ and $\beta$ chains (Supplementary Figure 1), and this condition was then chosen for subsequent assays. Proteolytic activity using albumin-depleted human plasma further confirmed fibrinogen degradation by proteinases present in the LPF supernatant (Supplementary Figure 1). Reduced amounts of leptospiral proteases can degrade fibrinogen. By contrast, plasminogen and thrombin were not susceptible to leptospiral proteases, as depicted in Figures 2C,D.

\section{Metalloproteases Secreted by L. interrogans Degrade Proteoglycans, Plasma Fibronectin and Fibrinogen}

To assess the class(es) of proteases involved in the degradation of host molecules, LPF supernatant was pretreated with inhibitors of serine, metallo-, cysteine, or aspartyl proteases before the addition of each substrate. In all cases, only 1,10-phenanthroline could fully inhibit the proteolytic activities, strongly suggesting the involvement of metalloproteases in this process (Figure 3, lane 4).

\section{Proteolytic Activity Against Host Molecules Correlates With L. interrogans Virulence}

To assess the proteolytic potential of additional Leptospira strains, we used a panel of seven Leptospira strains including one virulent (L. interrogans serovar Kennewicki strain Fromm, also called "LPF"), two saprophytes (L. biflexa serovar Patoc strain Patoc I and L. biflexa serovar Andamana strain CH11), and four culture-attenuated (L. interrogans serovar Copenhageni strain 10A, L. interrogans serovar Pomona strain Pomona, L. kirshneri serovar Cynopteri strain 3522 C and L. noguchi serovar Panama CZ 214). Strains LPF and Patoc I were used in the previous assays presented in Figures 1-3. Interestingly, proteolytic activity was only observed in the presence of the virulent strain LPF supernatant, thus indicating that production of proteases might be an important virulence determinant (Figure 4). Cultureattenuated or saprophytic Leptospira strains did not display a significant proteolytic activity against fibronectin, decorin or fibrinogen (Figure 4). Culture supernatants from the seven Leptospira strains used in this study were the same as those used in Fraga et al. (2014).

\section{Identification of Secreted Proteins From LPF and Patoc I Strains}

All secreted proteins identified in the LPF and Patoc I strains are shown in Supplementary Table 1. A total of 236 and 161 unique proteins were identified, respectively, in the LPF and in the Patoc I exoproteomes (Supplementary Tables 2, 3). Fifty proteins were detected in both strains (Supplementary Table 4). A search aiming to find proteases unique to the LPF exoproteome allowed identification of six peptidases, out of which three are metalloproteases (Table 1). One of them, a $52 \mathrm{kDa}$ protein belonging to the M43 family, harbors a pappalysin1 domain and contains a HEXXHXXGXXH zinc-dependent active site. Human pappalysin-1 is described as a secreted metalloprotease which cleaves insulin-like growth factor binding proteins (Oxvig, 2015). This protein also plays a role in bone formation, inflammation, wound healing and female fertility. A role for proteins containing pappalysin-1 domains remains to be exploited in bacteria. Another metalloprotease identified was TldD, a $49.9 \mathrm{kDa}$ protease containing the conserved HEXXH zinc-binding motif. TldD is quite conserved among prokaryotes, and plays a role in degrading unfolded proteins, as well as in the activation and degradation of natural products such as the peptide antibiotic microcin B17, peptide-derived cofactors or toxin-antitoxin modules (Ghilarov et al., 2017). The third metalloproatese identified was the 26.6 $\mathrm{kDa}$ methionine aminopeptidase (MAP) known to catalyze the hydrolytic cleavage of the N-terminal methionine from newly synthesized polypeptides. Apparently, neither of the three aforementioned proteases seems to be involved in gelatin hydrolysis since according to our zymography data gelatinolytic activity was associated with proteases of 72 and $42 \mathrm{kDa}$ (Figure 1F). Not infrequently, proteases are synthesized in very small quantities despite being highly efficient in hydrolyzing substrates, what may explain the non-detection of proteases presenting molecular masses of 72 and $42 \mathrm{kDa}$ in our proteomic analysis.

LPF and Patoc I secreted proteins were assigned to clusters of orthologous groups (COGs). Under molecular function the proteins were classified into the following categories: catalytic activity, binding, structural molecule activity, antioxidant activity, transporter activity, and nutrient reservoir activity. 


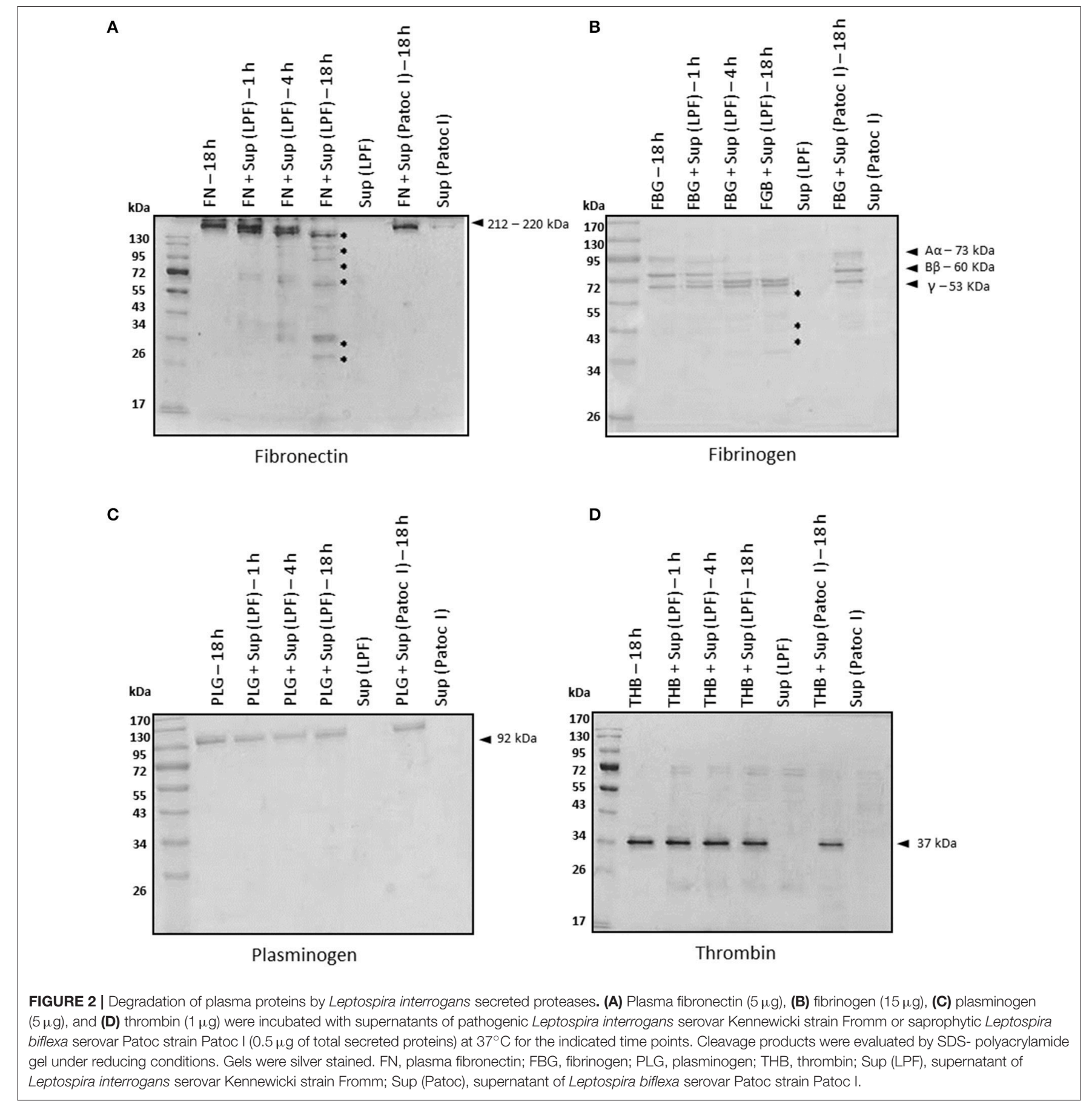

Proteins involved in catalytic activity and binding were the most represented in both LPF and Patoc I strains (Figure 5).

Using the MoonProt database (Mani et al., 2015), 25 proteins presumed to display moonlighting functions were detected (Supplementary Table 5). These multifunctional proteins play crucial roles in physiological processes, but have been shown to contribute to infection by many pathogens (Henderson, 2017). Housekeeping enzymes, including proteins from the glycolytic pathway, and chaperones are among the moonlighting proteins found in the exoproteomes.

\section{DISCUSSION}

Proteolytic activity targeting host molecules is a key strategy to facilitate the infection process of pathogens. Successful infection is not only achieved by the ability to circumvent host's innate immune defenses, but also by additional mechanisms that may aid bacteria to reach target organs. In this context, secreted proteases are of major importance for the infectious process. They are produced by pathogens including both Gram-positive and Gram-negative bacteria, viruses, and 

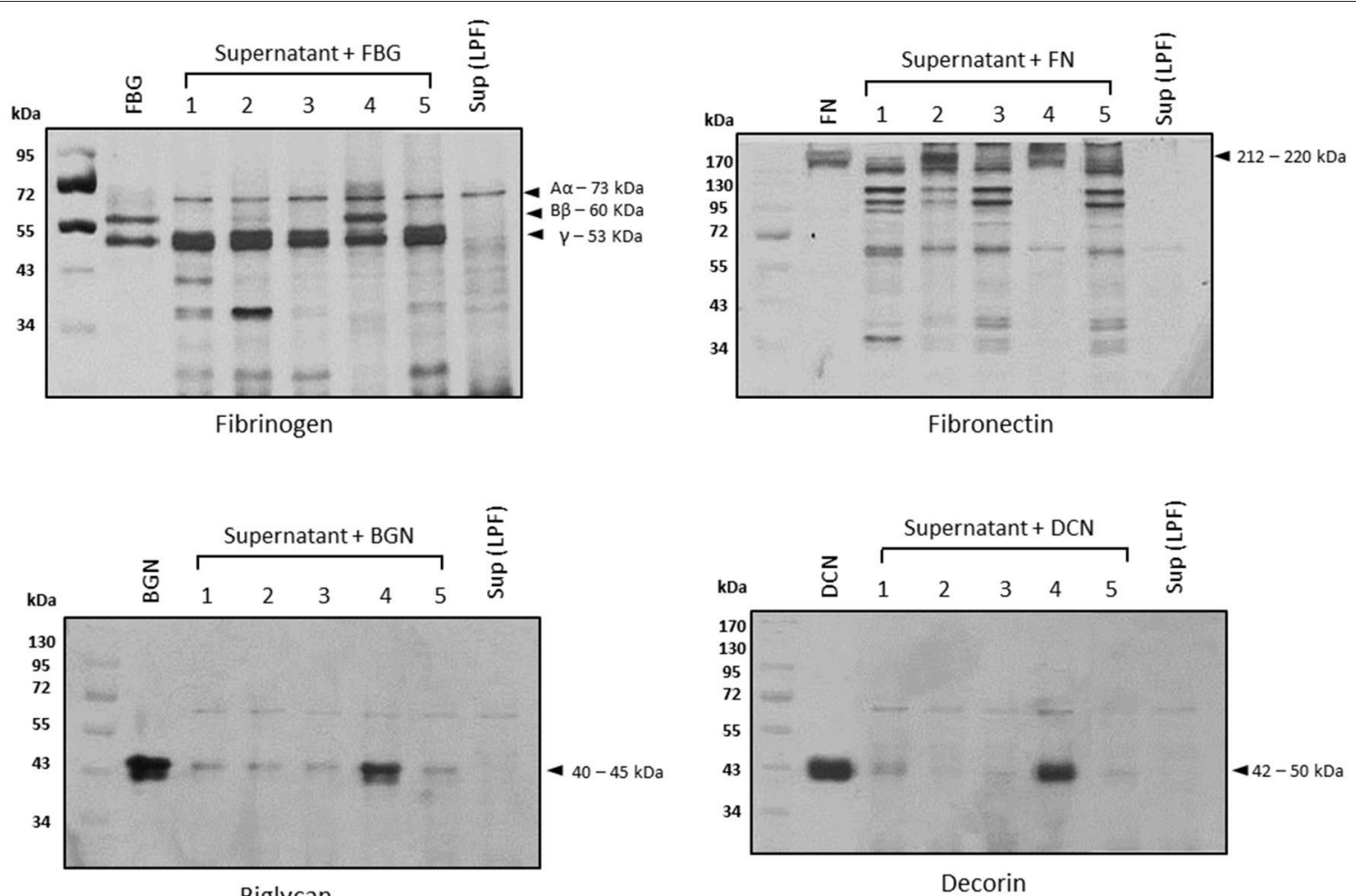

Biglycan

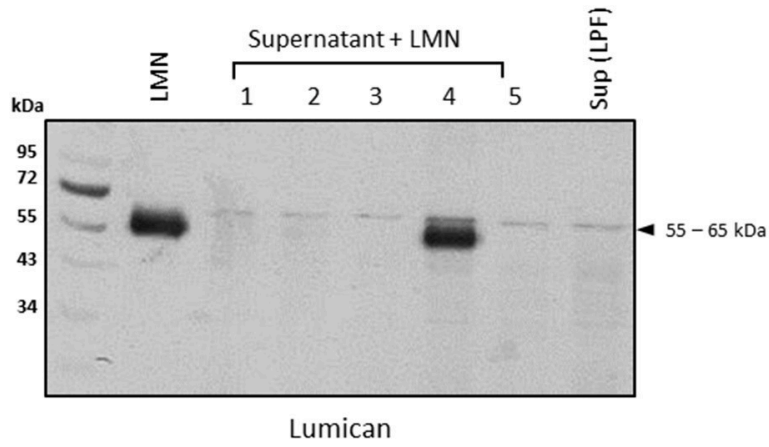

FIGURE 3 | Proteolytic activities are inhibited by 1,10-phenanthroline. Before the addition of each substrate, the supernatant of pathogenic Leptospira interrogans serovar Kennewicki strain Fromm ( $0.5 \mu \mathrm{g}$ of total secreted proteins) was incubated with inhibitors of serine proteases (5 mmol/L PMSF; lane 2), cysteine proteases (28 $\mu \mathrm{mol} / \mathrm{L} \mathrm{E-64;} \mathrm{lane} \mathrm{3),} \mathrm{metalloproteases} \mathrm{(5} \mathrm{mmol/L} \mathrm{1,10-phenanthroline;} \mathrm{lane} \mathrm{4),} \mathrm{or} \mathrm{aspartyl} \mathrm{proteases} \mathrm{(5} \mu \mathrm{mol} / \mathrm{L}$ pepstatin; lane 5) for $30 \mathrm{~min}$ at room temperature. Substrates were added and incubations proceeded for $18 \mathrm{~h}$. Cleavage products were analyzed by SDS- polyacrylamide gel under reducing conditions. Gels were silver stained. FBG, fibrinogen; FN, plasma fibronectin; BGN, biglycan; DCN, decorin; LMN, lumican; Sup (LPF), supernatant of Leptospira interrogans serovar Kennewicki strain Fromm.

fungi. A number of bacterial proteases contributing to invasion have been described to date. The alkaline protease (AprA), the proteases LasA, LasB, and protease IV from $P$. aeruginosa cause tissue damage during infections by inactivating components of the connective tissue (Schmidtchen et al., 2001). The same applies to Staphopain A (ScpA), aureolysin from Staphylococcus aureus and gelatinase (GelE) from Enterococcus faecalis which have been shown to degrade collagen, elastin and laminin, and also contribute to immune evasion (Park et al., 2008; Koziel and Potempa, 2013; Senyürek et al., 2014).
Pathogenic Leptospira are known to cross tissue barriers and rapidly reach the bloodstream. Target tissues are colonized even before bacterial multiplication (Wunder et al., 2016). Rapid dissemination within the host stems from leptospiral spiral shape associated with a translational motility, allowing them to efficiently swim in viscous gel-like environments (revised in Picardeau, 2017). In addition, proteases released during the initial stages of infection may also contribute to leptospiral invasion and immune evasion (Fraga et al., 2014). In this work, proteolytic activity of secreted leptospiral proteinases against some ECM components and human plasma proteins was 


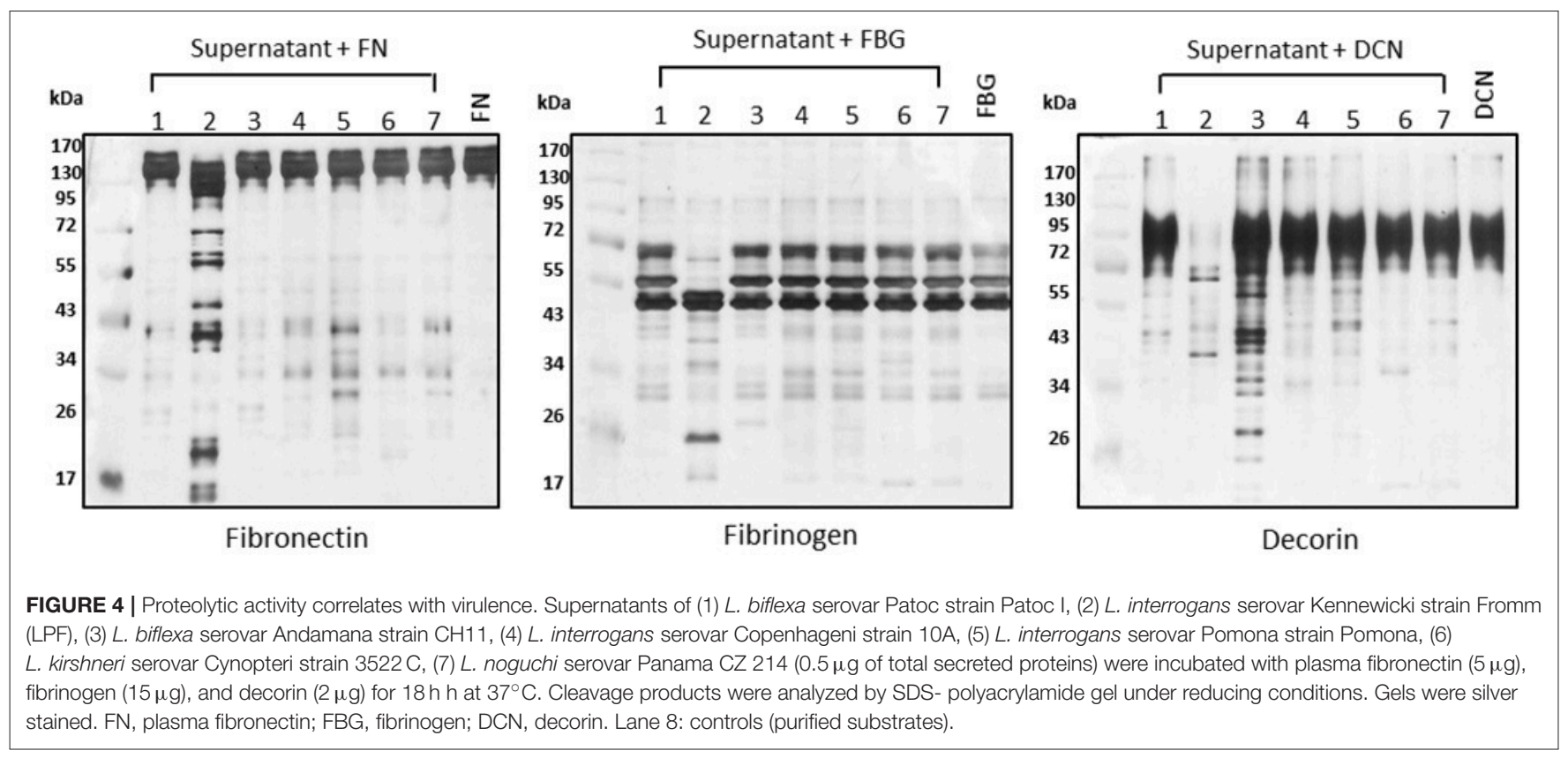

TABLE 1 | Proteases identified in the L. interrogans serovar Kennewicki strain Fromm (LPF) exoproteome.

\begin{tabular}{|c|c|c|c|}
\hline $\begin{array}{l}\text { EMBL } \\
\text { GenBank }\end{array}$ & Protein & Gene & Class \\
\hline EKO25673.1 & $\begin{array}{l}\text { Pappalysin-1 } \\
\text { domain protein }\end{array}$ & LEP1GSC104_4629 & Metallopeptidase \\
\hline AAN49383.1 & $\begin{array}{l}\text { Predicted } \\
\text { Zn-dependent } \\
\text { protease }\end{array}$ & $t / d D$ & Metallopeptidase \\
\hline AAN49656.2 & $\begin{array}{l}\text { Methionine } \\
\text { aminopeptidase }\end{array}$ & map & Metalloaminopeptidase \\
\hline EMP06453.1 & $\begin{array}{l}\text { Papain family } \\
\text { cysteine protease }\end{array}$ & LEP1GSC124_0278 & Cysteine peptidase \\
\hline M3CS93 & $\begin{array}{l}\text { ATP-dependent } \\
\text { protease ATPase } \\
\text { subunit HsIU }\end{array}$ & $h s / U$ & Peptidase \\
\hline AAN49152.2 & $\begin{array}{l}\text { ATP-dependent } \\
\text { Clp protease } \\
\text { proteolytic }\end{array}$ & $c / p P$ & Serine endopeptidase \\
\hline
\end{tabular}

evaluated. Proteases present in the culture supernatant of the virulent LPF strain degraded the small leucine-rich proteoglycans decorin, biglycan and lumican.

Ubiquitously distributed in the connective tissue, decorin interacts with multiple ECM compounds, being essential for matrix integrity. It is also involved in collagen fibrillogenesis, wound repair, angiostasis, tumor growth, and autophagy (Gubbiotti et al., 2016). Biglycan, another SLRP, is present in large quantities in skeletal and hard tissues (Wadhwa et al., 2004), but is also found in the kidneys (Schaefer et al., 2000), liver (Högemann et al., 1997), and skin (Fleischmajer et al., 1991). Like decorin and biglycan, lumican plays important roles in ECM organization and modulates biological processes, including regulation of collagen assembly into fibrils (McEwan et al., 2006; Schaefer and Iozzo, 2008; Stamov et al., 2013), and regulation of apoptosis, cell growth, invasion and angiogenesis (revised in Nikitovic et al., 2014). Interestingly, it has been shown that $L$. interrogans binds to proteoglycans expressed by mammalian cells (Breiner et al., 2009). Glycosaminoglycans (GAGs), covalently linked to proteoglycan core proteins, are the primary targets for leptospiral adhesion, and chondroitin sulfate $\mathrm{B}$ is the preferred GAG used for binding (Breiner et al., 2009). As decorin and biglycan are chondroitin sulfate/dermatan sulfate proteoglycans, we can speculate that these GAGs may serve as a platform for Leptospira anchoring, and subsequent local degradation of proteoglycan core proteins by bacterial secreted proteases.

On the assumption that basement membranes are also targeted by bacterial proteases, the effect of leptospiral secreted proteases on purified laminin and matrigel was also evaluated. Under our experimental conditions, these two substrates were not degraded. Gelatinolytic activity of Leptospira supernatants was evaluated by zymography. Proleotytic activity related to protein bands of approximately $72 \mathrm{kDa}$ and $42 \mathrm{kDa}$ was observed in gels co-polymerized with gelatin. A previous work by Madathiparambil et al. (2011) reported the presence of multiple gelatinases extracted from whole Leptospira ranging from 32 to $240 \mathrm{kDa}$. Some of them, including the ones detected in the present work, may be secreted during infection thus contributing to pathogenesis.

Proteolytic cleavage of plasma fibronectin and fibrinogen was also observed upon incubation with the culture supernatant of L. interrogans strain LPF. Purified fibrinogen and fibrinogen in human plasma were dose-dependently degraded by LPF proteases. Fibrinogen, a key clotting protein, plays a crucial role in coagulation and homeostasis. As a consequence of vascular damage, thrombin cleaves fibrinogen into insoluble 


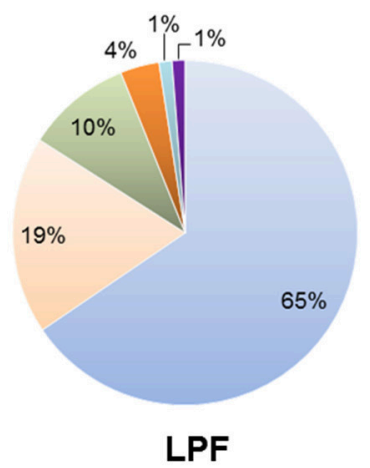

LPF

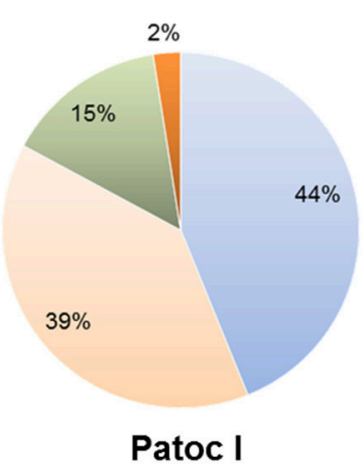

Patoc I

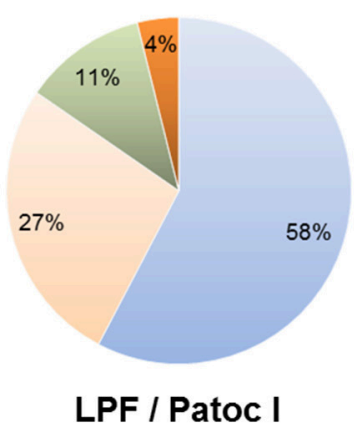

LPF I Patoc I

\footnotetext{
catalytic activity

binding

- structural molecule activity

= antioxidant activity

= transporter activity

nutrient reservoir activity
}

FIGURE 5 | Assignment of secreted proteins to Clusters of Orthologous Groups of proteins (COGs). The proteins identified in L. interrogans and L. biflexa exoproteomes were classified within the molecular function category. The predicted percentage of proteins in each subcategory is indicated. Pie charts of LPF unique proteins, Patoc I unique proteins and common proteins (LPF/Patoc I) are presented.

fibrin, triggering the fibrin network formation, essential for homeostasis. During infection several pathogens produce proteinases that degrade fibrinogen and, as a consequence, repair of injured sites is retarded (revised in Sun, 2006). One example is the treponemal metalloproteinase pallilysin (Tp0751), which in concert with the serine protease Tp0750, contributes to Treponema pallidum dissemination by inhibiting coagulation, promoting fibrinolysis, and degrading ECM components (Houston et al., 2011, 2012, 2014). Inflammation, vascular damage and lung hemorrhage are typical clinical manifestations of patients with severe leptospirosis (revised in Murray, 2015). Studies aiming to investigate whether these pathologies may be caused by fibrinogen-degrading proteinases of Leptospira are currently underway.

Thrombin and plasminogen, two other coagulation cascade molecules, were also incubated with Leptospira supernatants, and were not susceptible to degradation. It has been previously shown that Leptospira has multiple receptors for human plasminogen, and that, once bound to the bacterial surface, this host protease zymogen is converted to its active form, plasmin (Verma et al., 2010; Vieira et al., 2010; Nogueira et al., 2013; Wolff et al., 2013; Castiblanco-Valencia et al., 2016; Salazar et al., 2017). Since bound-plasmin(ogen) degrades ECM components and complement molecules in vitro (revised in Fraga et al., 2016), binding intact plasminogen may be more beneficial to the bacterium than degrading this zymogen.

By analyzing the proteolytic capacity of a larger number of strains, we found that culture-attenuated Leptospira strains failed to cleave ECM components, leading us to conclude that the proteases involved in this process are produced only under virulence conditions. Since 1,10-phenanthroline was an effective degradation inhibitor, it is presumed that metalloproteases were responsible for the majority of the observed proteolytic activity. Following these observations, proteomic analysis was performed in order to identify secreted proteases of virulent Leptospira that may be responsible for the degradation of host components. Among the proteases identified, pappalysin-1 domain protein deserves special attention. This metalloproteinase is well conserved among pathogenic Leptospira species according to Analysis Basic Local Alignment Search Tool (BLAST) analysis. A human ortholog, pregnancy-associated plasma protein-A (PAPPA), was initially described as an abundant placental protein detected in pregnant women. Further studies have shown that PAPP-A is expressed in a variety of tissues and is found tightly bound to GAGs on cell surfaces. This secreted metalloproteinase targets mainly insulin-like growth factor binding proteins (Oxvig, 2015). Functional characterization of Leptospira pappalysin-1 domain protein will be the subject of future studies of our group.

Furthermore, several moonlighting proteins were identified (Supplementary Table 5), thus endorsing previous exoproteomic data obtained from Leptospira culture supernatants (Eshghi et al., 2015). It is worth mentioning that the majority of moonlighting proteins reported by Eshghi and colleagues were also detected in our preparations, and among them are elongation Factor $\mathrm{Tu}$ (EF-Tu), enolase, and catalase. EF-Tu and enolase were described as plasminogen binding proteins (Nogueira et al., 2013; Wolff et al., 2013). They also interact with the complement regulators Factor $\mathrm{H}$ (EF-Tu) 
and C4b binding protein (C4BP) (Wolff et al., 2013; Salazar et al., 2017). Catalase is involved in oxidative stress resistance (Eshghi et al., 2012). By displaying additional functions related to interactions with host cells, some moonlighting proteins including glyceraldehyde 3-phosphate dehydrogenase (GAPDH) and fructose-1,6-biphosphate aldolase (FBA) are presumed to contribute to bacterial virulence (Henderson, 2017). However, as their canonical functions are generally associated with essential roles within the cell, and knockouts are generally non-viable, the assumption that they may contribute to bacterial virulence sometimes stems purely from in vitro experimentation. In addition, 15 out of 25 moonlighting proteins identified in our study were present in the saprophytic strain Patoc I (Supplementary Table 5), raising concerns about their role in virulence. For the moment, what can be assumed is that moonlighting proteins contribute to expand the functional proteome of a particular bacterium (Henderson, 2017). An obvious question that arises from our observations is how these and other proteins devoid of $\mathrm{N}$-terminal signal sequence or predicted to be exported through a non-classical secretory pathway are directed to the extracellular space. In line with the findings reported by Eshghi et al. (2015), around $60 \%$ of the proteins identified in the present study fall into this category. Whether Leptospira possesses particular export mechanisms remains an open question.

In conclusion, leptospiral extracellular proteases display proteolytic activity against proteoglycans and plasma proteins. The capacity to degrade host molecules correlates with Leptospira virulence, and may contribute to its dissemination potential.

\section{AUTHOR CONTRIBUTIONS}

LS performed most of the experiments and prepared all figures. MM contributed to sample preparation, proteomic data analysis, and aided in interpreting the results. EK contributed to proteomic execution. AO contributed to proteomic data analysis

\section{REFERENCES}

Amamura, T. A., Fraga, T. R., Vasconcellos, S. A., Barbosa, A. S., and Isaac, L. (2017). Pathogenic Leptospira secreted proteases target the membrane attack complex: a potential role for thermolysin in complement inhibition. Front. Microbiol. 8:958. doi: 10.3389/fmicb.2017.00958

Barbosa, A. S., Abreu, P. A., Vasconcellos, S. A., Morais, Z. M., Gonçales, A. P., Silva, A. S., et al. (2009). Immune evasion of Leptospira species by acquisition of human complement regulator C4BP. Infect. Immun. 77, 1137-1143. doi: 10.1128/IAI.01310-08

Barbosa, A. S., Monaris, D., Silva, L. B., Morais, Z. M., Vasconcellos, S. A., Cianciarullo, A. M., et al. (2010). Functional characterization of LcpA, a surface-exposed protein of Leptospira spp. that binds the human complement regulator C4BP. Infect. Immun. 78, 3207-3216. doi: 10.1128/IAI.00279-10

Breiner, D. D., Fahey, M., Salvador, R., Novakova, J., and Coburn, J. (2009). Leptospira interrogans binds to human cell surface receptors including proteoglycans. Infect. Immun. 77, 5528-5536. doi: 10.1128/IAI.00546-09

Castiblanco-Valencia, M. M., Fraga, T. R., Pagotto, A. H., Serrano, S. M., Abreu, P. A., Barbosa, A. S., et al. (2016). Plasmin cleaves fibrinogen and the human complement proteins $\mathrm{C} 3 \mathrm{~b}$ and $\mathrm{C} 5$ in the presence of Leptospira interrogans proteins: a new role of LigA and LigB in invasion and complement immune evasion. Immunobiology 221, 679-689. doi: 10.1016/j.imbio.2016.01.001 and provided a critical feedback. AA performed some of the experiments. GS provided all Leptospira strains used in the study. $\mathrm{MH}$ contributed to the analysis and interpretation of the data. LI provided critical feedback and helped shape the research. TF contributed to the design and implementation of the research. SS contributed with reagents, and performed the final proteomic analyses; contributed to the writing of the manuscript. $\mathrm{AB}$ conceived the study and was in charge of overall direction and planning, and wrote the manuscript.

\section{ACKNOWLEDGMENTS}

This work was supported by Fundação de Amparo à Pesquisa do Estado de São Paulo (FAPESP), grants \# 2014/00926-3 and 2013/17419-4 (fellowship for LS).

\section{SUPPLEMENTARY MATERIAL}

The Supplementary Material for this article can be found online at: https://www.frontiersin.org/articles/10.3389/fcimb. 2018.00092/full\#supplementary-material

Supplementary Figure 1 | Dose-dependent cleavage of purified and plasma fibrinogen. Leptospira interrogans serovar Kennewicki strain Fromm (LPF) supernatant (0.01-0.5 $\mu \mathrm{g}$ total secreted proteins) was incubated with $15 \mu \mathrm{g}$ of purified fibrinogen (A) or with human plasma containing an equivalent amount of fibrinogen (B) for $2 \mathrm{~h}$ at $37^{\circ} \mathrm{C}$. Cleavage products were analyzed by SDSpolyacrylamide gel under reducing conditions and gels were silver stained $(\mathbf{A})$ or submitted to Western blot and detected with anti-human fibrinogen (B). * cleavage products. FBG, fibrinogen.

Supplementary Table 1 | Identification of proteins in LPF and Patoc I strains by in solution tripsin digestion and LC-MS-MS analysis.

Supplementary Table 2 | Proteins identified only in the LPF strain.

Supplementary Table 3 | Proteins identified only in the Patoc I strain.

Supplementary Table 4 | Proteins identified in the supernatants of both LPF and Patoc I strains.

Supplementary Table 5 | Putative moonlighting proteins identified in LPF and Patoc I culture supernatants.

Chagnot, C., Listrat, A., Astruc, T., and Desvaux, M. (2012). Bacterial adhesion to animal tissues: protein determinants for recognition of extracellular matrix components. Cell Microbiol. 14, 1687-1696. doi: 10.1111/cmi. 12002

Cox, J., and Mann, M. (2008). MaxQuant enables high peptide identification rates, individualized p.p.b.-range mass accuracies and proteome-wide protein quantification. Nat. Biotechnol. 26, 1367-1372. doi: 10.1038/nbt.1511

Cox, J., Neuhauser, N., Michalski, A., Scheltema, R. A., Olsen, J. V., and Mann, M. (2011). Andromeda: a peptide search engine integrated into the MaxQuant environment. J. Proteome Res. 10, 1794-1805. doi: 10.1021/pr101065j

Eshghi, A., Lourdault, K., Murray, G. L., Bartpho, T., Sermswan, R. W., Picardeau, M., et al. (2012). Leptospira interrogans catalase is required for resistance to $\mathrm{H}_{2} \mathrm{O}_{2}$ and for virulence. Infect. Immun. 80, 3892-3899. doi: 10.1128/IAI.00466-12

Eshghi, A., Pappalardo, E., Hester, S., Thomas, B., Pretre, G., and Picardeau, M. (2015). Pathogenic Leptospira interrogans exoproteins are primarily involved in heterotrophic processes. Infect. Immun. 83, 3061-3073. doi: 10.1128/IAI.00427-15

Fleischmajer, R., Fisher, L. W., MacDonald, E. D., Jacobs, L. Jr., Perlish, J. S., and Termine, J. D. (1991). Decorin interacts with fibrillar collagen of embryonic and adult human skin. J. Struct. Biol. 106, 82-90. doi: 10.1016/1047-8477(91)90065-5 
Fraga, T. R., Courrol Ddos, S., Castiblanco-Valencia, M. M., Hirata, I. Y., Vasconcellos, S. A., Juliano, L., et al. (2014). Immune evasion by pathogenic Leptospira strains: the secretion of proteases that directly cleave complement proteins. J. Infect. Dis. 209, 876-886. doi: 10.1093/infdis/jit569

Fraga, T. R., Isaac, L., and Barbosa, A. S. (2016). Complement evasion by pathogenic Leptospira. Front. Immunol. 7:623. doi: 10.3389/fimmu.2016.00623

Ghilarov, D., Serebryakova, M., Stevenson, C. E. M., Hearnshaw, S. J., Volkov, D. S., Maxwell, A., et al. (2017). The origins of specificity in the microcin-processing protease TldD/E. Structure 25, 1549-1561.e5. doi: 10.1016/j.str.2017.08.006

Gubbiotti, M. A., Vallet, S. D., Ricard-Blum, S., and Iozzo, R. V. (2016). Decorin interacting network: a comprehensive analysis of decorinbinding partners and their versatile functions. Matrix Biol. 55,7-21. doi: 10.1016/j.matbio.2016.09.009

Hashimoto, V. L., Abreu, P. A., Carvalho, E., Gonçales, A. P., Morais, Z. M., Vasconcellos, S. A., et al. (2013). Evaluation of the elastinolytic activity and protective effect of Leptallo, I., a protein composed by metalloprotease and FA5/8C domains, from Leptospira interrogans Copenhageni. Microb. Pathog. 61-62, 29-36. doi: 10.1016/j.micpath.2013.04.011

Henderson, B. (2017). Moonlighting Proteins: Novel Virulence Factors in Bacterial Infections. Hoboken, NJ: Wiley-Blackwell

Högemann, B., Edel, G., Schwarz, K., Krech, R., and Kresse, H. (1997). Expression of biglycan, decorin and proteoglycan-100/CSF-1 in normal and fibrotic human liver. Pathol. Res. Pract. 193, 747-751. doi: 10.1016/S0344-0338(97)80052-0

Houston, S., Hof, R., Francescutti, T., Hawkes, A., Boulanger, M. J., and Cameron, C. E. (2011). Bifunctional role of the Treponema pallidum extracellular matrix binding adhesin Tp0751. Infect. Immun. 79, 1386-1398. doi: 10.1128/IAI.01083-10

Houston, S., Hof, R., Honeyman, L., Hassler, J., and Cameron, C. E. (2012). Activation and proteolytic activity of the Treponema pallidum metalloprotease, pallilysin. PLoS Pathog. 8:e1002822. doi: 10.1371/journal.ppat.1002822

Houston, S., Russell, S., Hof, R., Roberts, A. K., Cullen, P., Irvine, K., et al. (2014). The multifunctional role of the pallilysin-associated Treponema pallidum protein, Tp0750, in promoting fibrinolysis and extracellular matrix component degradation. Mol. Microbiol. 91, 618-634. doi: 10.1111/mmi.12482

Kassegne, K., Hu, W., Ojcius, D. M., Sun, D., Ge, Y., Zhao, J., et al. (2014). Identification of collagenase as a critical virulence factor for invasiveness and transmission of pathogenic Leptospira species. J. Infect. Dis. 209, 1105-1115. doi: 10.1093/infdis/jit659

Koziel, J., and Potempa, J. (2013). Protease-armed bacteria in the skin. Cell Tissue Res. 351, 325-337. doi: 10.1007/s00441-012-1355-2

Levett, P. N. (2001). Leptospirosis. Clin. Microbiol. Rev. 14, 296-326. doi: 10.1128/CMR.14.2.296-326.2001

Madathiparambil, M. G., Cattavarayane, S., Manickam, G. D., Singh, K., Perumana, S. R., and Sehgal, S. C. (2011). A zymography analysis of proteinase activity present in Leptospira. Curr. Microbiol. 62, 917-922. doi: 10.1007/s00284-010-9810-3

Mani, M., Chen, C., Amblee, V., Liu, H., Mathur, T., Zwicke, G., et al. (2015). MoonProt: a database for proteins that are known to moonlight. Nucleic Acids Res. 43, D277-D282. doi: 10.1093/nar/gku954

McEwan, P. A., Scott, P. G., Bishop, P. N., and Bella, J. (2006). Structural correlations in the Family of small leucine-rich repeat proteins and proteoglycans. J. Struct. Biol. 155, 294-305. doi: 10.1016/j.jsb.2006.01.016

Meri, T., Murgia, R., Stefanel, P., Meri, S., and Cinco, M. (2005). Regulation of complement activation at the C3-level by serum resistant leptospires. Microb. Pathog. 39, 139-147. doi: 10.1016/j.micpath.2005.07.003

Murray, G. L. (2015). The molecular basis of leptospiral pathogenesis. Curr. Top. Microbiol. Immunol. 387, 139-185. doi: 10.1007/978-3-662-45059-8_7

Nikitovic, D., Kouvidi, K., Voudouri, K., Berdiaki, A., Karousou, E., Passi, A., et al. (2014). The motile breast cancer phenotype roles of proteoglycans/glycosaminoglycans. Biomed. Res. Int. 2014:124321. doi: $10.1155 / 2014 / 124321$

Nogueira, S. V., Backstedt, B. T., Smith, A. A., Qin, J. H., Wunder, E. A. Jr., Ko, A., et al. (2013). Leptospira interrogans enolase is secreted extracellularly and interacts with plasminogen. PLoS ONE 8:e78150. doi: 10.1371/journal.pone.0078150

Oxvig, C. (2015). The role of PAPP-A in the IGF system: location, location, location. J. Cell Commun. Signal. 9, 177-187. doi: 10.1007/s12079-015-0259-9.

Park, S. Y., Shin, Y. P., Kim, C. H., Park, H. J., Seong, Y. S., Kim, B. S., et al. (2008). Immune evasion of Enterococcus faecalis by an extracellular gelatinase that cleaves C3 and iC3b. J. Immunol. 181, 6328-6336. doi: 10.4049/jimmunol.181.9.6328

Picardeau, M. (2017). Virulence of the zoonotic agent of leptospirosis: still terra incognita? Nat. Rev. Microbiol. 15, 297-307. doi: 10.1038/nrmicro.2017.5

Rappsilber, J., Mann, M., and Ishihama, Y. (2007). Protocol for micro-purification, enrichment, pre-fractionation and storage of peptides for proteomics using StageTips. Nat. Protoc. 2, 1896-1906. doi: 10.1038/nprot.2007.261

Salazar, N., Souza, M. C., Biasioli, A. G., Silva, L. B., and Barbosa, A. S. (2017). The multifaceted roles of Leptospira enolase. Res. Microbiol. 168, 157-164. doi: 10.1016/j.resmic.2016.10.005

Schaefer, L., Gröne, H. J., Raslik, I., Robenek, H., Ugorcakova, J., Budny, S., et al. (2000). Small proteoglycans of normal adult human kidney: distinct expression. patterns of decorin, biglycan, fibromodulin, and lumican. Kidney Int. 58, 1557-1568. doi: 10.1046/j.1523-1755.2000.00317.x

Schaefer, L., and Iozzo, R. V. (2008). Biological functions of the small leucinerich proteoglycans: from genetics to signal transduction. J. Biol. Chem. 283, 21305-21309. doi: 10.1074/jbc.R800020200

Schmidtchen, A., Wolff, H., and Hansson, C. (2001). Differential proteinase expression by Pseudomonas aeruginosa derived from chronic leg ulcers. Acta Derm. Venereol. 81, 406-409. doi: 10.1080/000155501317208336

Senyürek, I., Kempf, W. E., Klein, G., Maurer, A., Kalbacher, H., Schäfer, L., et al. (2014). Processing of laminin $\alpha$ chains generates peptides involved in wound healing and host defense. J. Innate Immun. 6, 467-484. doi: 10.1159/000357032

Stamov, D. R., Müller, A., Wegrowski, Y., Brezillon, S., and Franz, C. M. (2013). Quantitative analysis of type I collagen fibril regulation by lumican and decorin using AFM. J. Struct. Biol. 183, 394-403. doi: 10.1016/j.jsb.2013.05.022

Subramanian, S. (1984). Dye-ligand affinity chromatography: the interaction of Cibacron Blue F3GA with proteins and enzymes. CRC Crit. Rev. Biochem. 16, 169-205. doi: 10.3109/10409238409102302

Sun, H. (2006). The interaction between pathogens and the host coagulation system. Physiology (Bethesda) 21, 281-288. doi: 10.1152/physiol.00059.2005

Tyanova, S., Temu, T., Sinitcyn, P., Carlson, A., Hein, M. Y., Geiger, T., et al. (2016). The Perseus computational platform for comprehensive analysis of (prote)omics data. Nat. Methods 13, 731-740. doi: 10.1038/nmeth.3901

Verma, A., Brissette, C. A., Bowman, A. A., Shah, S. T., Zipfel, P. F., and Stevenson, B. (2010). Leptospiral endostatin-like protein A is a bacterial cell surface receptor for human plasminogen. Infect. Immun. 78, 2053-2059. doi: 10.1128/IAI.01282-09

Vieira, M. L., Atzingen, M. V., Oliveira, T. R., Oliveira, R., Andrade, D. M., Vasconcellos, S. A., et al. (2010). In vitro identification of novel plasminogenbinding receptors of the pathogen Leptospira interrogans. PLoS ONE 5:e11259. doi: 10.1371/journal.pone.0011259

Wadhwa, S., Embree, M. C., Bi, Y., and Young, M. F. (2004). Regulation, regulatory activities, and function of biglycan. Crit. Rev. Eukaryot. Gene Expr. 14, 301-315. doi: 10.1615/CritRevEukaryotGeneExpr.v14.i4.50

Wiśniewski, J. R., Zougman, A., Nagaraj, N., and Mann, M. (2009). Universal sample preparation method for proteome analysis. Nat. Methods 6, 359-362. doi: $10.1038 /$ nmeth. 1322

Wolff, D. G., Castiblanco-Valencia, M. M., Abe, C. M., Monaris, D., Morais, Z. M., Souza, G. O., et al. (2013). Interaction of Leptospira elongation factor $\mathrm{Tu}$ with plasminogen and complement factor $\mathrm{H}$ : a metabolic leptospiral protein with moonlighting activities. PLOS ONE 8:e81818. doi: 10.1371/journal.pone.0081818

Wunder, E. A. Jr., Figueira, C. P., Santos, G. R., Lourdault, K., Matthias, M. A., Vinetz, J. M., et al. (2016). Real-Time PCR reveals rapid dissemination of Leptospira interrogans after intraperitoneal and conjunctival inoculation of hamsters. Infect. Immun. 84, 2105-2115. doi: 10.1128/IAI.00094-16

Conflict of Interest Statement: The authors declare that the research was conducted in the absence of any commercial or financial relationships that could be construed as a potential conflict of interest.

Copyright (c) 2018 da Silva, Menezes, Kitano, Oliveira, Abreu, Souza, Heinemann, Isaac, Fraga, Serrano and Barbosa. This is an open-access article distributed under the terms of the Creative Commons Attribution License (CC BY). The use, distribution or reproduction in other forums is permitted, provided the original author(s) and the copyright owner are credited and that the original publication in this journal is cited, in accordance with accepted academic practice. No use, distribution or reproduction is permitted which does not comply with these terms. 